\title{
Reflets
}

Revue ontaroise d'intervention sociale et communautaire

\section{Santé des organismes communautaires inc.}

\section{Lise Nolet}

Volume 5, numéro 2, automne 1999

La santé des francophones de l’Ontario

URI : https://id.erudit.org/iderudit/026289ar

DOI : https://doi.org/10.7202/026289ar

Aller au sommaire du numéro

Éditeur(s)

Reflets : Revue ontaroise d'intervention sociale et communautaire

ISSN

1203-4576 (imprimé)

1712-8498 (numérique)

Découvrir la revue

Citer cet article

Nolet, L. (1999). Santé des organismes communautaires inc. Reflets, 5(2),

285-287. https://doi.org/10.7202/026289ar

Tous droits réservés (C) Reflets : Revue ontaroise d'intervention sociale et communautaire, 1999

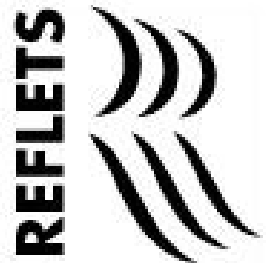

Ce document est protégé par la loi sur le droit d'auteur. L'utilisation des services d'Érudit (y compris la reproduction) est assujettie à sa politique d'utilisation que vous pouvez consulter en ligne.

https://apropos.erudit.org/fr/usagers/politique-dutilisation/ 


\title{
Santé des organismes communautaires inc.
}

\author{
Lise $\mathrm{N}$ olet \\ coordonnatrice de projets
}

\section{L'organisme}

Santé des organismes communautaires inc. (SO CI) est un nouvel organisme à but non-lucratif qui a été créé pour administrer le programme de révisions et d'accréditation des Centres de santé communautaires (CSC) en 0 ntario. L'intention de ce programme est de mesurer de façon objective la performance des CSC, de promouvoir l'amélioration continue de services de qualité, d'identifier et partager des exemples de programmes et de services innovateurs. Le programme existe sur une base volontaire, donc les C SC sont libres d'y participer ou non. Présentement, 50 des 54 C SC participent au programme.

SO CI fut créé en 1998 lors d'une rencontre de l'A ssociation des centres de santé communautaires (ACSO) pour discuter du processus d'accréditation. Les membres présents de C SC ont convenu qu'il serait préférable de créer un nouvel organisme indépendant de l'AC SO pour mener à bien cette tâche. La raison d'être d'une organisation indépendante est d'assurer la confidentialité des résultats lors du processus de révision. 


\section{Les réviseures et les réviseurs}

La révision en vue de l'accréditation est effectuée par des pairs auxquels se joint une employée du bureau de SO CI. Les pairs sont soit du personnel, soit des membres siégeant au conseil d'administration des C.S.C en 0 ntario.Avant de devenir réviseurs ou réviseures, ces personnes reçoivent une formation offerte par les employées de $\mathrm{SO} \mathrm{Cl}$ et se sont familiarisées avec la trousse d'examen «B âtir des organismes plus sains » (BO S).

Les employées de SO CI s'assurent que les pairs envisagés pour agir comme réviseurs ou réviseures n'ont pas de conflits d'intérêt avec les C SC soumis à l'examen. D e plus, les employées de $\mathrm{SO} C \mathrm{I}$ s'assurent que les individus choisis apportent une variété de compétences et d'expériences, afin d'assurer un bon équilibre sur chaque équipe de révision. Certaines des compétences ou expériences recherchées ont trait à la gouvernance, la gestion, la promotion de la santé, les sciences de la santé et le travail social.

\section{Le matériel de révision}

Le matériel utilisé pour effectuer le processus d'accréditation est la trousse d'examen «Bâtir des organismes plus sains » (BOS). C ette trousse fut développée par le $G$ roupe de travail de la gestion de la qualité, formé de représentants des C SC, de l'A ssociation des C entres de santé de I'O ntario (ACSO ) et du M inistère de la santé.

La trousse traite des thèmes suivants: la gouvernance, les systèmes administratifs, le travail communautaire, la gestion et les programmes et services. C haque C SC a en sa possession un manuel du BOS. 


\section{Le processus de révision}

Le processus de révision comprend quatre composantes: les sondages auprès des partenaires communautaires du C SC, la visite des lieux et des programmes du CSC, les entrevues auprès des employés et des membresdu conseil d'administration et la révision de divers documents produits par le C SC.

\section{Les Centres de santé en Ontario}

O n retrouve présentement 54 CSC en 0 ntario. Parmi ces C SC, cinq offrent uniquement des services en français. $C$ eux-ci sont situésà N ew Liskeard, Sudbury, C ornwall,Toronto et $\mathrm{H}$ amiltonWelland. Par ailleurs, certains CSC ailleurs en province offrent certains services en français.

Les C SC se distinguent par leurs services multidisciplinaires qui comprennent des services de santé, de santé mentale, de prévention et de promotion de la santé, de développement communautaire.

Note

Pour de plus amples renseignements sur le programme de révision et d'accréditation pour des CSC, veuillez communiquer avec Lise N olet au (416) 239-2448, poste 223 ou par courrier électronique à cohipc@interlog.com. 